\title{
Biological screening of Ajuga iva extracts obtained by supercritical carbon dioxide and pressurized liquid extraction
}

\author{
Hamdi Bendif ${ }^{1,2 *}$, Mohamed Lazali³, Mohammed Harir ${ }^{2}$, Mohamed Djamel \\ Miara $^{2}$, Messaoud Boudjeniba ${ }^{1}$ and Petras Rimantas Venskutonis ${ }^{4}$ \\ ${ }^{1}$ Laboratory of Ethnobotany and natural substances, Department of Natural Sciences, ENS- \\ Kouba, B.P 92, Algiers, Algeria. \\ ${ }^{2}$ Département des sciences de la nature et de la vie. Université de M'Sila. 28000. Algeria. \\ ${ }^{3}$ Faculte des Sciences de la Nature et de la Vie \& des Sciences de la Terre, Universite de Khemis \\ Miliana, Route Theniet El Had, Soufay, 44225 Khemis Miliana, Algeria. \\ ${ }^{4}$ Department of Food Science and Technology, Kaunas University of Technology, Radvilenu pl. 19, \\ LT-50254, Lithuania.
}

\begin{abstract}
Extracts obtained by supercritical carbon dioxide extraction (SCE) and pressurized liquid extraction (PLE) from the Ajuga iva aerial parts growth in three different geographical sites of Alegria were analysed. Tocopherols in SCE Extracts were quantified by HPLC, $\alpha$-tocopherol dominated the profile in both $A$. iva of Bejaia (BEJ) and Bordj Bou Arreridj (BBA), while $\beta$-tocopherol was the lowest. PLE method produced higher extraction yields than SCE method, which ranged from 0.31 to $24.95 \%$ (w/w), the water gave the best yields extraction. Total phenolic content (TPC) ranged from 15.60 to $63.45 \mathrm{mg}$ GAE/g DWE; also the water gave higher total yield of phenolics, and the best TPC from DWP. The antioxidant activity was assessed by different assays, water and SCE extracts showed a slightly higher antioxidative effect than that obtained by Ethanol and Acetone. A slight opposite trend was obtained with the FRAP antioxidant activity; Acetone was the best extract after SCE extracts. Small differences in antioxidant activity values were found between the different sites of A. iva: BEJ, BBA, and ELO.
\end{abstract}

Key words:

Antioxidant activity, Ajuga iva, SCE, DPPH•, FRAP, H-ORAC, L-ORAC
Received:

11 June 2017

\section{Accepted:}

29 July 2017

Published:

02 August 2017

*Corresponding Author: Hamdi Bendif Département des sciences de la nature et de la vie. Université de M'Sila. 28000, Algeria

Email:

bendif_hamdi@ yahoo.fr

\section{Citation:}

Bendif H., Lazali, M., Harir, M., Miara, M. D., Boudjeniba, M. \& Venskutonis, P. R. (2017). Biological screening of Ajuga iva extracts obtained by supercritical carbon dioxide and pressurized liquid extraction. Journal of Medicinal Botany, 1, 3341. doi: 10.25081/jmb.2017.v1.816

\section{Introduction}

The genus Ajuga (Lamiaceae) comprises 4050 species, which grow in different parts of the world (Tsurng-Juhn et al., 2009), mainly in the temperate and warm temperate zones (Yusuke et al., 2013). Ajuga plants are evergreen, clumpforming rhizomatous perennial or annual herbaceous flowering species, $5-50 \mathrm{~cm}$ tall, with opposite leaves. The flowers are two lipped and tubular, and mostly blue, purple or yellow in color. Many Ajuga plants are used in horticulture as groundcover or border, and in rock gardens, but some are regarded as weeds. Some Ajuga species have a large number of varieties (Zafar and Badiâa, 2009). A. iva is a common species in North Africa (Ayari et al., 2013), which is widely distributed in the Mediterranean region, particularly in Algeria, Morocco, Tunisia, and Egypt, southern Europe and northern Africa

CThis article is open access and licensed under the terms of the Creative Commons Attribution License (http://creativecommons.org/licenses/by/4.0/) which permits unrestricted, use, distribution and reproduction in any medium, or format for any purpose, even commercially provided the work is properly cited. Attribution - You must give appropriate credit, provide a link to the license, and indicate if changes were made. 
(Halimi, 2004). In Algeria A. iva, Schreiber it is known as "Chendgoura" (Taleb-Senouci et al., 2009). A. iva Grows in deep soil, its vegetation period is from spring to late summer, it flowers between May and June (Halimi, 2004).

Several Ajuga species have been used in African and Asian folk medicine (El Hilaly et al., 2004). In Algeria it has been used in phytomedicine for a variety of diseases and disorders (Taleb-Senouci et al., 2009), such as diabetes (Tahraoui et al., 2007), stomach and intestinal pains, enteritis, fever, sinusitis, headache (Ghedira et al., 1991); rheumatism, gout, asthma, malaria, ulcers and diarrhea. Antibacterial, antitumor, antifeedant, vulnerary properties were reported for the preparations from Ajuga species (Chenni et al., 2007; Chabane et al., 2013).

Pharmacological studies have shown that A. iva possesses anti-ulcerous (Habib et al., 1990) and anti-inflammatory activities (El Hilaly and Lyoussi, 2002); its extract decreased plasma cholesterol and triglycerides (El Hilaly et al., 2006). The powdered dried plant or its infusion are taken after meals against diabetes and hypertension; the infusion of flowering branches is considered as antidiarrheic, depurative, and very effective substances for feminine sterility (Ghedira et al., 1991).

Other reported biological effects of $A$. iva include hypoglycemic (El Hilaly and Lyoussi, 2002), vasorelaxant (El Hilaly et al., 2004), hypolipidemic (El Hilaly et al., 2006), hypotensive, antioxidant (Chenni et al., 2007), anti-inflammatory, antifungal, antimicrobial, antipyretic, antihelmintic, and vulnerary activity (El Hilaly and Lyoussi, 2002; El Hilaly et al., 2004, 2006). Chemical studies on $A$. iva have revealed the presence of several flavonoids, tannins, terpenes, steroids (Houghton and Raman, 1998), and essential oil constituents $A$. iva (Ayari et al., 2013). Until now, mostly conventional extraction procedures have been used to botanicals, which are usually time and solvent consuming.
PLE and SCE are the more recent and promising alternatives for the isolation of valuable substances from medicinal and other plant materials (Herrero et al., 2006). PLE uses organic solvents or water at high pressures enabling to in increase extraction temperatures above their boiling point at atmospheric pressure. Meanwhile SCE with environmentally safe $\mathrm{CO}_{2}$ as a solvent has recently become another attractive way to obtain solvent-free extracts with minimized alternations of labile ingredients present in the plants (Cavero et al., 2006). SCE in adition $\mathrm{CO}_{2}$, which is the most commonly used solvent in SCE, has low critical constants and low viscosity enabling it to penetrate the materials being extracted. However, $\mathrm{CO}_{2}$ as a nonpolar solvent is not able to extract polar analytes from the solid matrices (Reverchon \& de Marco, 2006).

The present investigation is the first to evaluate the influence of method of extraction (PLE and SCE) and type of solvent (acetone, ethanol, and water), on the levels of yield of extraction, phenolic content (TPC), and the Antioxidant activity.

\section{Materials and methods \\ Solvents and chemicals}

Solvents and chemicals used in the experiments were of analytical grade and obtained from standard chemical suppliers.

\section{Samples preparation and extraction}

Mature aerial parts of $A$. iva were collected between April and May 2013, from the sites of Bejaia (BEJ), Bordj Bou Arreridj (BBA), El Oued (ELO) (Table 1), with difrferent climatic conditions. The plants were authenticated as A. iva by Dr M. DJ. Miara, Msila University (Algeria), the samples were washed by the running water, and then dried at room temperature in the dark. They were ground in an ultra-centrifugal mill ZM 200 (Retsch, Haan, Germany) using $0.2 \mathrm{~mm}$ hole size sieve before extractions. The extraction was done as explained in Šulniūtè et al. (2016).

Table 1. Location, main ecological traits of the analysed populations of Ajuga iva (L.).

\begin{tabular}{llllll}
\hline Plant région & Latitude & Longitude & Altitude $(\mathrm{m})$ & $\mathrm{Q}^{\mathrm{a}}$ & Bioclimatic \\
\hline Bejaia & $36^{\circ} .71^{\prime} \mathrm{N}$ & $05^{\circ} 06 \mathrm{E}$ & 2 & 87 & humid \\
Bordj Bou Arreridj & $36^{\circ} .06^{\prime} \mathrm{N}$ & $04^{\circ} 76 \mathrm{E}$ & 930 & 23 & semi-arid \\
El Oued & $33^{\circ} .36^{\prime} \mathrm{S}$ & $06^{\circ} 85 \mathrm{E}$ & 80 & 7,56 & arid \\
\hline
\end{tabular}

${ }^{a}$ Bioclimatic zones were defined according to Emberger's (1966) pluviometric coefficient. 


\section{Determination of tocopherols in SCE extracts by HPLC}

An HPLC was used for the quantitative determination of tocopherols in the lipophilic extarcts isolated by SCE as described by Gruszka and Kruk (2007).

\section{In vitro antioxidant activity assessment}

To obtain more comprehensive data on antioxidant potential of $A$. iva, four different assays were used to evaluate the in vitro antioxidant activity of extracts.

Total phenolic content (TPC) was measured by Folin-Ciocalteu's assay (Singleton et al., 1999). DPPH• assay was assessed according to the procedure described by Srinivasan et al. (2007). Total antioxidant activity of compounds was investigated using FRAP assay (Müller et al., 2011). Hydrophilic-oxygen radical absorbance capacity (H-ORAC) assay was done by method of Prior et al. (2003). Lipophilic oxygen radical absorbance capacity (L-ORAC) assay for SCE Extracts was conducted by the method of Prior et al. (2003).

\section{Expression of data and statistical analysis}

All extractions and analyses were carried out in triplicate, and Data were presented as means \pm SD. A computer program Graph pad prism 6 was used for statistical analysis. The one-way
ANOVA and Tukey's multiple comparisons test were performed to examine the differences among the groups. A $\mathrm{P}$ value of $<0.05$ was considered to be statistically significant.

\section{Results and discussion Tocopherol Contents of SCE Extracts}

In humans, the Tocopherols act mainly as Vitamin E precursors and they have some role in the prevention of some chronic diseases and certain cancers, and found mainly in leaves and seeds (Hachicha et al., 2009). Tocopherol contents of the SCE extracts as $(\alpha, \beta, \gamma, \delta)(\mu \mathrm{g}$ tocopherol/g DWE) from tow Algerian AI (BEJ and $\mathrm{BBA}$ ) are given in Table 2, $\alpha$-tocopherol dominated the profile in both AI, at $3290 \pm 0.27$ and $1580 \pm 0.03 \mu \mathrm{g} / \mathrm{g}$ DWE respectively, while $\beta$-tocopherol is the lowest and was only 150 $\mu \mathrm{g} / \mathrm{g}$ DWE detected in AI extracts.

Regarding the site of harvest, the highest content was found in AI from BEJ, for all type of tocopherol. SCE Extracts are a potential source of tocopherol, with a total tocopherol contents ranged from 150 to $3290 \mu \mathrm{g} / \mathrm{g}$ DWE. This value is similar to those of green leaves of many plant species, where $\alpha$-tocopherol was the most abundant form of tocopherols (Lars et al., 2010).

Table 2. SCE-CO $\mathrm{CO}_{2}$ Extracts Tocopherol Contents ( $\left.\mu \mathrm{g} / \mathrm{g}\right)$ of Ajuga iva L.

\begin{tabular}{lll}
\hline$\mu \mathrm{g}$ tocopherol /g DWE Ajuga iva & & \\
\hline type & BEJ & BBA \\
\hline$\delta$-tocopherol & $180 \pm 0.02$ & $150 \pm 0.02$ \\
$\gamma$-tocopherol & $700 \pm 0.11$ & $220 \pm 0.02$ \\
$\beta$-tocopherol & $150 \pm 0.02$ & $150 \pm 0.08$ \\
$\alpha$-tocopherol & $3290 \pm 0.27$ & $1580 \pm 0.03$ \\
\hline
\end{tabular}

BEJ:Bejaia, BBA:Bordj Bou Arreridj

Table 3. Extract yields (\%) and TPC of different Extracts of Ajuga iva obtained by SFE and PLE methods.

\begin{tabular}{|c|c|c|c|c|c|c|c|c|c|c|}
\hline \multirow[t]{3}{*}{ Samples } & & \multicolumn{3}{|c|}{ Yield \% w/w (g/100 g DWP) } & \multicolumn{6}{|c|}{ TPC mg GAE/g } \\
\hline & & \multirow{2}{*}{$\mathrm{BEJ}$} & \multirow{2}{*}{ BBA } & \multirow{2}{*}{ ELO } & \multicolumn{2}{|l|}{ BEJ } & \multicolumn{2}{|l|}{$\mathrm{BBA}$} & \multicolumn{2}{|l|}{ ELO } \\
\hline & & & & & DWE & DWP & DWE & DWP & DWE & DWP \\
\hline$\overline{\mathrm{SCE}-\mathrm{CO} 2}$ & Extracts & $0,38 \pm 0,01^{\mathrm{d}}$ & $0,48 \pm 0,00^{\mathrm{h}}$ & $0,31 \pm 0,00^{1}$ & -nd & -nd & -nd & -nd & -nd & -nd \\
\hline PLE & Acetone & $1,32 \pm 0,00^{a}$ & $1,52 \pm 0,04^{\mathrm{e}}$ & $2,25 \pm 0,08^{\mathrm{i}}$ & $54,37 \pm 0,77 \mathrm{ab}$ & $0.83 \pm 0.01^{\mathrm{abc}}$ & $55,27 \pm 0,20^{\text {ba }}$ & $0.84 \pm 0.00^{\text {bac }}$ & $43,83 \pm 1,32^{\mathrm{cf}}$ & $0.99 \pm 0.03^{\mathrm{cabf}}$ \\
\hline Extracts & Ethanol & $2,71 \pm 0,03^{\mathrm{b}}$ & $3,77 \pm 0,04^{\mathrm{f}}$ & $2,56 \pm 0,05 j$ & $63,45 \pm 0,80^{\mathrm{d}}$ & $1.72 \pm 0.02^{\mathrm{de}}$ & $47,51 \pm 0.79^{\mathrm{ef}}$ & $1,79 \pm 0.03^{\mathrm{ed}}$ & $45,69 \pm 0,92^{\text {fec }}$ & $1.17 \pm 0.02^{\mathrm{fc}}$ \\
\hline & Water & $21,70 \pm 0,35^{c}$ & $24,95 \pm 0,67 \mathrm{~g}$ & $24,10 \pm 0,05^{\mathrm{k}}$ & $25,18 \pm 0.88^{g}$ & $5.40 \pm 0.19 \mathrm{gi}$ & $15,60 \pm 0.36^{\mathrm{h}}$ & $3,82 \pm 0.09^{\mathrm{h}}$ & $21,51 \pm 1.04^{\mathrm{i}}$ & $5,18 \pm 0.25^{\mathrm{ig}}$ \\
\hline
\end{tabular}

Values represented as mean \pm standard deviation $(n=3)$; different lowercase superscript letters within the columns indicate significant differences between SCE- $\mathrm{CO}_{2}$; Acetone; Methanol and Water extracts and between region of recolte, at $<0.05$. BEJ:Bejaia, BBA:Bordj Bou Arreridj, ELO : El oued. 


\section{Extraction yields}

A comparative study of extraction yield was carried out in order to test optimum condition of extraction, by usig SCE and PLE extraction methods using consecutive application of solvents with increasing polarity such as Acetone, Ethanol, and Water. The results of extract yield (expressed as weight of extract relative to the weight of the starting plant material) are given in Table 3. It can be seen that the yield of extraction using PLE method increased with increasing polarity of solvents, ranged from $0.31 \pm 0.00$ to $24.95 \pm 0.67 \%$. In which water extracts gave the highest yield from all sites, while ethanol and acetone gave lower yields, the yields of SCE extraction were remarkably lower compared to PLE extracts.

The extraction yield of AI is significantly influenced by the methods and solvents of extraction $(\mathrm{P}<0.05)$, But no significant change in extraction yield from plant sites was recorded. These results showed that the solvent polarity is of great importance (Clara et al., 2010). In fact, since Water and Ethanol are a polar solvent, the polar components from AI be extracted. Thus, the variation in the yields of various extracts can be attributed to the polarities of the different compounds. Such differences have been reported in the literature (Khlifi et al., 2011). These findings were in agreement with (El Hilaly et al., 2004) in AI water extract $(25 \%(w / w))$, The close finding is reported for other lamiaceae such as T. vulgaris, Salvia officinalis and Origanum majorana (Roby et al., 2013), Thymus numidicus (Ben El Hadj Ali et al., 2014).

\section{Antioxidant activity}

Five methods have been used to measure the antioxidant activities of the AI extracts: TPC, DPPH•, FRAP, H-ORAC, and L-ORAC assays.

\section{Total phenolic contents (TPC)}

TPC reflects the total reducing capacity of the sample, The TPC of extracts obtained by PLE extraction by three different solvents with varying polarities (Acetone, Ethanol, and Water) is reported in Table 3. Significant differences $(p<$ $0.0001)$ in TPC values were observed among different solvents. The TPC were in the range of $15,60 \pm 0.36$ to $63,45 \pm 0,80 \mathrm{mg}$ GAE /g DWE and from $0.83 \pm 0.01$ to $5.40 \pm 0.19 \mathrm{mg} \mathrm{GAE} / \mathrm{g}$ DWP.

The highest values were determined for Ethanol and Acetone extracts, followed by Water extracts, it may be suggested that Acetone enables to obtain from AI the extract with the highest TPC value. The TPC which is extracted by different solvents from $1 \mathrm{~g}$ of DWP is also presented and in this case Water provides the highest TPC followed by Ehanol, whereas Acetone extracts contained the lowest TPC in $1 \mathrm{~g}$ of DWP, Polar phenolic compounds are better extracted with higher polarity organic solvents.

The close finding is reported for Ajuga iva Makni et al. (2013), and for other lamiaceae such as T. vulgaris, Salvia officinalis and Origanum majorana (Roby et al., 2013), R. officinalis and Origanum vulgare (Hernandez-Hernandez et al., 2009). This might be due to the differences between AI samples and TPC evaluation methods used in these studies. The total phenolic contents varied not significantly among the studied sites in the different extracts of AI (Table 3).

\section{$\mathrm{DPPH} \bullet$ assay results}

In the present study, the different extracts of AI showed a DPPH $\bullet$-scavenging activity which varied among the different extracts. As shown in Table 4, scavenging activity of the extracts is concentration dependent and lower IC50 value reflects better protective action.

The $\mathrm{IC}_{50}$ values of the antioxidant capacity varied from 0.39 to $1.37 \mathrm{mg} / \mathrm{mL}$. The Water and SCE extracts possessed the strongest $\mathrm{DPPH} \bullet$ scavenging activity, showing a lowest $\mathrm{IC}_{50}$ ranged from 0.39 to $0.68 \mathrm{mg} / \mathrm{ml}$. followed by Acetone extracts and Water extracts in both BEJ, BBA, and ELO, while that of the synthetic antioxidant Trolox was IC50 $=0.01 \mathrm{mg} / \mathrm{ml}$, as a standard reference product.

Our results confirmed previous studies showing a same antioxidant activity of Ajuga iva methanolic extracts $1.168 \pm 0.003 \mathrm{mg} / \mathrm{mL}$ (Khaled-Khodja et al., 2014). The data were expressed also as TEAC $\mathrm{DPPH} \cdot \mathrm{mg} \mathrm{TE} / \mathrm{g}$ in DWE and DWP (Table 4). it was varied significantly (P $<0.05)$ from 8.12 to $17.75 \mathrm{mg}$ TE/g DWE. And from 0.03 to $4.27 \mathrm{TE} / \mathrm{g}$ DWP.

It can be seen that water and SCE extracts shows the highest $\mathrm{TEAC}_{\mathrm{DPpH}}$. followed by 
Ethanol extracts. However, due to differences in extract yields (Table 3), TEAC $\mathrm{DPPH}_{\text {• as }} \mathrm{mg} \mathrm{TE} / \mathrm{g}$ in DWP were in another range: the least effective extract was SCE (0.03 to $0.06 \mathrm{mg}$ TE/g DWP) and the most effective one was water extracts, in contrast, both PLE Ethanol and Acetone extracts showed weak antioxidant capacity.

It can be seen that Water extracts showed the highest antioxidant activity among the PLE extracts, On the other hand, the antioxidant activity of SCE Extracts is more effective. This can be attributed to the higher phenolic content of the Water extracts than that of ethanaloic and acetonic extracts. Previous published papers on Ajuga iva demonstrated that methanol extracts showed the highest antioxidant activities than Water extracts (Makni et al., 2013). In conclusion, this study indicates that AI Water extracts improves the best antioxidant status

\section{FRAP assay results}

The antioxidant capacities of SCE, and PLE extracts (Acetone, Ethanol, and Water) expressed as TEAC FRAP $\mathrm{mg}$ TE/g in DWP and DWE are given in Table 5. The TEAC $\mathrm{C}_{\mathrm{FAP}}$ values were in a range: $(19.91 \pm 0.03$ to $64.50 \pm 1.43$ $\mathrm{mg}$ TE/g DWE), and (0.07 \pm 0.00 to $5.80 \pm 0.15$ mg TE/g DWP) for all extracts, SCE Extracts had the highest antioxidant capacity as TEAC $\mathrm{FRAP}$ in mg TE/g DWE, followed by Acetone, Water and Ethanol (PLE extracts). But The values expressed as $\mathrm{mg}$ TE/g DWP, showed Water extracts have a higher TEAC FRAP than others (Table 5), and the lowest was SCE Extracts, This due to differences in extract yields (Table 3). Regarding site effect, no significant differences in TEACFRAP values were found between BEJ, $\mathrm{BBA}$, and ELO extracts.

\section{H-ORAC assay results}

The antioxidant capacity (expressed as ORAC value) is shown in Table 6. The strongest TEAC $_{\text {H-ORAC }}$ expressed as $\mu \mathrm{M}$ TE/g DWE for both extracts sites was noticed for ethanol and acetone extracts followed by Water extracts, whereas SCE Extracts gave the least TEAC $\mathrm{H}_{-}$ ORAC value in both AI extracts.

But the TEAC ${ }_{\text {H-ORAC }}$ expressed as $\mu \mathrm{M} \mathrm{TE} / \mathrm{g}$ DWP indicated that Water extracts have the higher values and SCE Extracts gave the lowest values (Table 6). TEAC H-ORAC values as measured by ORAC assay were significantly different $\mathrm{P}<0,0001$, with ethanol extracts more active than others. However, taking into account the yields of extraction, Water extracts were more active. The literature contains very few studies about the antioxidant activity measurement by the ORAC method.

Table 4. The antioxidant characteristics of different Ajuga iva L. Extracts. DPPH and IC50 values.

\begin{tabular}{|c|c|c|c|c|c|c|c|c|c|c|}
\hline & & \multicolumn{6}{|c|}{ TEAC } & \multicolumn{3}{|c|}{$\begin{array}{l}\text { DPPH assay }\left(\mathrm{IC}_{50},\right. \\
\mathrm{mg} / \mathrm{ml})\end{array}$} \\
\hline & & \multicolumn{2}{|l|}{ BEJ } & \multicolumn{2}{|l|}{ BBA } & \multicolumn{2}{|l|}{ ELO } & \multirow{2}{*}{ BEJ } & \multirow{2}{*}{ BBA } & \multirow{2}{*}{ ELO } \\
\hline & & DWE & DWP & DWE & DWP & DWE & DWP & & & \\
\hline \multicolumn{2}{|c|}{ SCE-CO2 Extracts } & $16.37 \pm 0.11^{\mathrm{afkl}}$ & $0.06 \pm 0.00^{\mathrm{abcd}}$ & $9.25 \pm 0.00^{\text {bcdghi }}$ & $0.04 \pm 0.00^{\mathrm{bac}}$ & $8.91 \pm 1.32^{\text {cbdghi }}$ & $0.03 \pm 0.00^{\text {cab }}$ & 0,5 & 0,48 & 0,39 \\
\hline PLE & Acetone & $9.49 \pm 0.34 \mathrm{dbcghi}$ & $0.14 \pm 0.01$ daei & $12.28 \pm 0.23^{e}$ & $0.19 \pm 0.00^{\text {edgi }}$ & $15.47 \pm 0.00^{\mathrm{fak}}$ & $0.35 \pm 0.00^{\mathrm{fh}}$ & 1,19 & 0,94 & 0,73 \\
\hline \multirow[t]{2}{*}{ Extracts } & Ethanol & $8.99 \pm 0.54 \mathrm{gbcdhi}$ & $0.24 \pm 0.01$ gehi & $8.12 \pm 0.04^{\mathrm{hbcdgi}}$ & $0.31 \pm 0.00^{\mathrm{hfg}}$ & $8.38 \pm 0.25^{\text {ibcdgh }}$ & $0.21 \pm 0.01^{\mathrm{ideg}}$ & 1,21 & 1,32 & 1,37 \\
\hline & Water & $18.39 \pm 0.1^{\mathrm{jk}}$ & $3.94 \pm 0.02^{i}$ & $17.17 \pm 0.2^{\mathrm{kafjl}}$ & $4.20 \pm 0.05^{\mathrm{kl}}$ & $17.75 \pm 0.2^{\mathrm{lajk}}$ & $4.27 \pm 0.05^{\mathrm{lk}}$ & 0,56 & 0,68 & 0,63 \\
\hline Trolox & & & & & & & & 0,01 & & \\
\hline
\end{tabular}

Values represented as mean \pm standard deviation $(n=3)$; different lowercase superscript letters within the columns indicate significant differences between SCE-CO2; Acetone; Methanol and Water extracts and between region of recolte, at $<0.05$. BEJ:Bejaia, BBA:Bordj Bou Arreridj, ELO : El oued.

Table 5. The antioxidant characteristics of different Ajuga iva L. Extracts FRAP

\begin{tabular}{|c|c|c|c|c|c|c|c|}
\hline \multirow{3}{*}{\multicolumn{2}{|c|}{ Samples }} & \multicolumn{6}{|c|}{$\mathrm{TEAC}_{\text {FRAP }}, \mathrm{mg}$ TE/g } \\
\hline & & \multicolumn{2}{|l|}{ BEI } & \multicolumn{2}{|l|}{$\mathrm{BBA}$} & \multicolumn{2}{|l|}{ ELO } \\
\hline & & DWE & DWP & DWE & DWP & DWE & DWP \\
\hline \multicolumn{2}{|c|}{ SCE-CO2 Extracts } & $58,26 \pm 1.02^{\text {afghijkl }}$ & $0.07 \pm 0.00^{\text {ac }}$ & $64,50 \pm 1.43^{\mathrm{bc}}$ & $0.31 \pm 0.02^{\mathrm{bc}}$ & $58,81 \pm 1.04^{\mathrm{cb}}$ & $0.19 \pm 0.02^{\mathrm{cab}}$ \\
\hline PLE & Acetone & $33.44 \pm 1.01^{\text {defghijklf }}$ & $0.51 \pm 0.02^{\text {degi }}$ & $37.94 \pm 0.03^{\text {edfii }}$ & $0,57 \pm 0.00^{\text {edfgi }}$ & $32.49 \pm 0.05^{\text {fadeghijkl }}$ & $0,73 \pm 0.00^{\text {feghi }}$ \\
\hline \multirow[t]{2}{*}{ Extracts } & Ethanol & $22,51 \pm 0.18^{\text {gadfhijkl }}$ & $0,61 \pm 0.00$ gdefi & $20.93 \pm 0.04^{\text {hadfgijkl }}$ & $0,79 \pm 0.00^{\mathrm{hfi}}$ & $24.28 \pm 0.13^{\text {iadefghjkl }}$ & $0,62 \pm 0.00^{\text {idefgh }}$ \\
\hline & Water & $27,06 \pm 0.69^{\text {jadefghikl }}$ & $5,80 \pm 0.15$ & $20,30 \pm 0.01^{\text {kadfghijl }}$ & $4.97 \pm 0.00^{\mathrm{kl}}$ & $19,91 \pm 0.03^{\text {ladfghijk }}$ & $4,79 \pm 0.01^{\mathrm{lk}}$ \\
\hline
\end{tabular}

Values represented as mean \pm standard deviation $(n=3)$; different lowercase superscript letters within the columns indicate significant differences between SCE-CO2; Acetone; Methanol and Water extracts and between region of recolte, at $<0.05$. BEJ:Bejaia, BBA:Bordj Bou Arreridj, ELO : El oued. 
Table 6. The antioxidant characteristics of different Ajuga iva L. Extracts. H ORAC and L ORAC

\begin{tabular}{|c|c|c|c|c|c|c|c|}
\hline \multirow{3}{*}{\multicolumn{2}{|c|}{ Samples }} & \multicolumn{6}{|c|}{ TEAC $_{\text {H-ORAC, }} \mu \mathrm{M}$ TE/g } \\
\hline & & \multicolumn{2}{|l|}{ BEJ } & \multicolumn{2}{|l|}{$\mathrm{BBA}$} & \multicolumn{2}{|l|}{ ELO } \\
\hline & & DWE & DWP & DWE & DWP & DWE & DWP \\
\hline \multicolumn{2}{|c|}{ SCE-CO2 Extracts } & $183.62 \pm 7.99^{\mathrm{acd}}$ & $0,72 \pm 0.05 i$ & $159.12 \pm 5.56^{\mathrm{b}}$ & $0,80 \pm 0.01^{\mathrm{k}}$ & $128.93 \pm 1.37 \mathrm{cad}$ & $0,42 \pm 0.01^{1}$ \\
\hline PLE & Acetone & $243.17 \pm 1.61^{\mathrm{dac}}$ & $3.70 \pm 0.02^{\mathrm{ab}}$ & $244.62 \pm 2.26^{\mathrm{efh}}$ & $3.71 \pm 0.00^{\mathrm{ba}}$ & $259.93 \pm 3.96^{\text {fegh }}$ & $5.85 \pm 0.09^{c}$ \\
\hline \multirow[t]{2}{*}{ Extracts } & Ethanol & $243.64 \pm 5.366^{\mathrm{ff}}$ & $6.60 \pm 0.15^{\mathrm{d}}$ & $213.72 \pm 3.76^{\text {hef }}$ & $8.05 \pm 0.14^{e}$ & $274.33 \pm 7.51^{\mathrm{i}}$ & $7.03 \pm 0.19^{\mathrm{f}}$ \\
\hline & Water & $231.90 \pm 11.64 j$ & $49.74 \pm 2.50^{\mathrm{g}}$ & $231.98 \pm 11.64^{\mathrm{k}}$ & $56.78 \pm 2.85^{\mathrm{h}}$ & $231.71 \pm 11.65^{1}$ & $55.76 \pm 2.80^{\mathrm{i}}$ \\
\hline \multicolumn{2}{|c|}{$\begin{array}{l}\text { SCE-CO2 Extracts TEAC }{ }_{L} \\
\text { ORAC, } \mu \mathrm{M} \text { TE } / g\end{array}$} & $101,293 \pm 2.4^{a}$ & $0.69 \pm 0.03^{\mathrm{A}}$ & $97,630 \pm 2.37^{b}$ & $0.76 \pm 0.03^{\mathrm{B}}$ & $93,566 \pm 3.17 \mathrm{c}$ & $0.41 \pm 0.00^{\mathrm{C}}$ \\
\hline
\end{tabular}

Values represented as mean \pm standard deviation $(n=3)$; different lowercase superscript letters within the columns indicate significant differences between SCE-CO2; Acetone; Methanol and Water extracts and between region of recolte, at $<0.05$. BEJ:Bejaia, BBA:Bordj Bou Arreridj, ELO : El oued.

\section{L-ORAC assay results}

For this work, the L-ORAC assay was to measure radical chain breaking capacity of lipophilic fraction obtained by SCE. As presented in Table 6, TEAC ${ }_{\text {L-ORAC values were in }}$ the range of 93.56 and $101.29 \mu \mathrm{M}$ TE/g DWE for both extracts.

Such high TEAC values could be explained by the presence of lipophilic antioxidants, like tocopherol (Table 2), when recalculated per $g$ of DWP, the activity of AI lipophilic fraction amounted 0.41 to $0.76 \mu \mathrm{M}$ TE/g, both H ORAC and L-ORAC assays indicate higher share of AI lipophilic fraction to the radical scavenging capacity. Our SCE Extracts exhibited highest TEAC ${ }_{\text {L-ORAC value when compared with Teucrium }}$ species seed oil of which ranged between 14.58 and $296 \mathrm{mg} / \mathrm{kg}$ (Hachicha et al., 2009).

Correlation between TPC, TEAC DPPH., TEAC $_{\text {FRAP, }}$ and TEAC ${ }_{\mathrm{H} \text { ORAC }}$

Correlation coefficients for different antioxidant assays are presented in Table 7 and 8.
It may be observed that there are strong correlations between different antioxidant activity assays when the values are expressed for plant material DWP Table 8. However, when antioxidant activity values are expressed for $g$ of extract DWE, the correlations are more complicated.

The most assays revealed that Water extracts have a higher antioxidant activity than Ethanol, Acetone, and SCE. a significant positive correlation between all antioxidant activities values expressed as $\mathrm{mg}$ in $\mathrm{g}$ DWP were observed indicating that extracts with highest polyphenol contents show higher TEAC DPPH $\bullet$, TEAC FRAP, and TEAC $\mathrm{H}$ ORAC for PLE Extracts. But antioxidant activity values expressed as $\mathrm{mg}$ in $\mathrm{g}$ DWE. In the present study, a negative significant correlations estimated by the spearman's coefficient, were observed only between TEAC DPPH $\bullet$ and TPC, TEAC FRAP, and between TEAC H-ORAC and TEAC FRAP (Table 7).

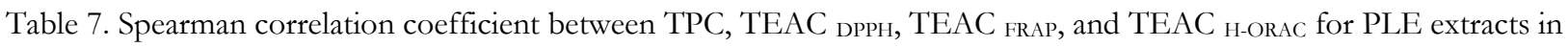
DWE.

\begin{tabular}{lllll}
\hline & $\begin{array}{l}\text { mgGAE/g } \\
\text { DWE }\end{array}$ & $\begin{array}{l}\text { TEAC DPPH mg } \\
\text { TE/g DWE }\end{array}$ & $\begin{array}{l}\text { TEAC FRAP mg } \\
\text { troE/g DWE }\end{array}$ & $\begin{array}{l}\text { TEAC ORAC mg } \\
\text { TE/g DWE }\end{array}$ \\
\hline mgGAE/g DWE & 1,00 & & & \\
TEAC DPPH mg TE/g DWE & $-0,83$ & 1,00 & & \\
TEAC FRAP mg troE/g DWE & 0,46 & $-0,42$ & 1,00 & 1,00 \\
TEAC ORAC $\mathrm{mg}$ TE/g DWE & 0,30 & 0,17 & $-0,65$ & \\
\hline
\end{tabular}

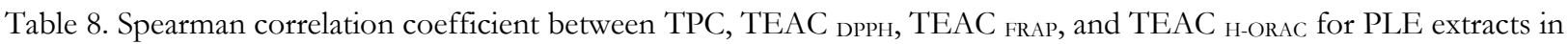
DWP.

\begin{tabular}{lllll}
\hline & $\begin{array}{l}\text { mgGAE/g } \\
\text { DWP }\end{array}$ & $\begin{array}{l}\text { TEAC DPPH, mg } \\
\text { TE/g DWP }\end{array}$ & $\begin{array}{l}\text { TEAC FRAP mg } \\
\text { TE/g DWP }\end{array}$ & $\begin{array}{l}\text { TEAC ORAC mg } \\
\text { TE/g DWP }\end{array}$ \\
\hline mgGAE/g DWP & 1,00 & & & \\
TEAC DPPH, mg TE/g DWP & 0,95 & 1,00 & & \\
TEAC FRAP mg TE/g DWP & 0,97 & 0,99 & 1,00 & 1,00 \\
TEAC ORAC mg TE/g DWP & 0,95 & 1,00 & 0,98 & \\
\hline
\end{tabular}




\section{Conclusion}

In summary, using two different methods for extraction, it has been confirmed that both PLE and SCE extraction of AI show substantial AA. The PLE extraction with water was more effective than the SCE extraction because of the higher extraction yield. SCE extraction, which allows a fractionated separation of volatile components and fatty-waxy products, might be advantageous method. The combination of a first step SCE extraction and a PLE extraction step might be still more efficient to decrease the AI variety of the extract while preserving its antioxidant properties.

\section{Author contributions}

Hamdi Bendif and Mohamed Djamel Miara collected the plant and drafted the manuscript; Lazali Mohamed and Harir Mohamed and Messaoud Boudjeniba interpreted the Biological screening data. Rimantas Venskutonis, supervised the supercritical carbon dioxide and pressurized liquid extraction and revised the manuscript. All the authors agreed the final version of manuscript for publishing in Journal of Medicinal Botany.

\section{References}

Ayari B., leila R., Sana Z., Hnia C., Ahmed M., 2013. Evaluation of antioxidant and antimicrobial activities of tunisian Ajuga iva L. essential oils, revue f. s. b xi.

Ben El Hadj Ali I., Bahri R., Chaouachi M., Boussaïd M., Harzallah-Skhiri F., 2014. Phenolic content, antioxidant and allelopathic activities of various extracts of Thymus numidicus Poir. Organs, Industrial Crops and Products 62, 188-195.

Cavero S., Garcia-Risco M.R., Marin F.R., Jaime L., Santoyo S., Javier-Senorans F., Reglero G., \& Ibanez E. 2006. Supercritical fluid extraction of antioxidant compounds from oregano. Chemical and functional characterization via LC MS and in vitro assays. The Journal of Supercritical Fluids, 38, 62-69.

Chabane D., Saidi F., Rouibi A. Azine K., 2013. Activité hypoglycémique de l'extrait aqueux d'Ajuga iva L. schreber chez les rats diabétiques induite par l'alloxane, Afrique Science 09 (1) 120-127.

Chenni, D., Ait Yahia, F.O., Boukortt, J., Prost, M.A., Lacaille-Duboisc, M.B., 2007. Effect of aqueous extract of Ajuga iva supplementation on plasma lipid profile and tissue antioxidant status in rats fed a high-cholesterol diet, Journal of Ethnopharmacology. 109, 207213.

Clara Grosso, Ana Cristina Figueiredo, Jesus Burillo, Ana M. Mainar, Jose' S. Urieta, Jose' G. Barroso, Jose' A. Coelho, Anto'nio M. F. Palavra, 2010. Composition and antioxidant activity of Thymus vulgaris volatiles: Comparison between supercritical fluid extraction and hydrodistillation, J. Sep. Sci. 33, 2211-2218.

El Hilaly J., Lyoussi B., 2002. Hypoglycaemic effect of the lyophilised aqueous extract of Ajuga iva in normal and streptozotocin diabetic rats. J. Ethnopharmacol. 80,109113.

El Hilaly J., Israili Z.H., Lyoussi B., 2004. Acute and chronic toxicological studies of Ajuga iva in experimental animals, Journal of Ethnopharmacology 91, 43-50.

El-Hilaly J., Tahraoui A., Israili Z.H. Lyoussi B. 2006. Hypolipidemic effects of acute and sub-chronic administration of an aqueous extract of Ajuga iva L. whole plant in normal and diabetic rats. Journal of Ethnopharmacology 105, 441-448.

Emberger, L. (1966). Une classification biogéographique des climats. Recherches et travaux des laboratoires de géologie, botanique et zoologie. Faculté des Sciences, Montpellier,

France, 7, 1.

Ghedira K., R. Chemli, B. Richard, M. Zeches, L. and Le- Men-Olivier. 1991. Contribution à l'étude de la pharmacopée traditionnelle de Tunisie: Étude des parties aeriennes d' Ajuga iva L. Schreb. Plantes- Medicinales-etPhytotherapie, 25, 100-111.

Gruszka J., Kruk J., 2007. RP-LC for determination of plastochromanol, tocotrienols and tocopherols in plant oils, chromatoghraphia 66, 909-913.

Habib J., F., Ben Douissa, K., Ghedira, A., Toumi, R. and Chemli, 1990. Contribution à l'étude de la pharmacopée traditionnelle de Tunisie: Activité anti-ulcéreuse d' Ajuga iva, Rhus oxyacantha et Teucrium polium, Ethnopharmacologie: sources, méthodes, 
objectifs, Paris, Metz, ORSTOM et SCE, 387-388.

Hachicha S. F., Barrek S., Skanji T., Zarrouk H., and Ghrabi Z. G., 2009. Fatty acid, tocopherol, and sterol content of three Teucrium species from tunisia, Chemistry of Natural Compounds, Vol. 45, No. 3.

Halimi A.K. 2004. Les plantes médicinales en Algérie. 1ère édition. BERTI Editions, Alger. pp: 156- 157.

Hernandez-Hernandez E., Ponce-Alquicira E., Jaramillo-Flores M.E., Legarreta G.L., 2009. Antioxidant effect of rosemary (Rosmarinus officinalis L.) and oregano (Origanum vulgare L.) extracts on TBARS and colour of model raw batters. Meat Sci. 81, 410-417.

Herrero M., Cifuentes A., Ibanez E., 2006. Suband supercritical fluid extraction of functional ingredients from different natural sources: plants, food-by-products, Algae and Microalgae: A Review, Food Chem. 98, 136148.

Houghton P.J., Raman A., 1998. Laboratory Hand Book for the Fractionation of Natural Extracts, $1^{\text {st }}$ ed. ITPs, London

Khaled-Khodja Nabyla, Boulekbache-Makhlouf Lila, Madanib Khodir, 2014. Phytochemical screening of antioxidant and antibacterial activities of methanolic extracts of some Lamiaceae, Industrial Crops and Products 61, 41-48.

Khlifi D., Hamdi M., El Hayouni A., Cazaux S., Souchard J.P., Couderc F., Bouajila J., 2011. Global chemical composition and antioxidant and anti-tuberculosis activities of various extracts of Globularia alypum L. (Globulariaceae) leaves. Molecules 16, 1059210603.

Lars M., Kathleen T. and Volker B., 2010. In vitro antioxidant activity of tocopherols and tocotrienols and comparison of vitamin $\mathrm{E}$ concentration and lipophilic antioxidant capacity in human plasma, Mol. Nutr. Food Res., 54, 731-742.

Makni M., Haddar A., Kriaa W., Zeghal N., 2013. Antioxidant, free radical scavenging, and antimicrobial activities of Ajuga iva leaf extracts. International Journal of Food Properties, 16, 756-765.

Müller L., Fröhlich K., Böhm V., 2011. Comparative antioxidant activities of carotenoids measured by ferric reducing antioxidant power (FRAP), ABTS bleaching assay ( $\alpha$ TEAC), DPPH• assay and peroxyl radical scavenging assay. Food Chem. 129:139-148.

Prior R.L., Hoang H., Gu L., Wu X., Bacchiocca M., Howard L., Hampsch-Woodill M., Huang D., Ou B., Jacob R., 2003. Assays for hydrophilic and lipophilic antioxidant capacity (oxygen radical absorbance capacity (ORACFL) of plasma and other biological and food samples. J. Agric. Food Chem. 51, 3273-3279.

Reverchon E., 1997. Supercritical fluid extraction and fractionation of essential oils and related products. J. Supercrit. Fluids. 10 (1), 1-37.

Roby M.H.H., Sarhana M.A., Selima K.A.H., Khalel K.I., 2013. Evaluation of antioxidant activity, total phenols and phenolic compounds in thyme (Thymus vulgaris L.), sage (Salvia officinalis L.), and marjoram (Origanum majorana L.) extracts. Ind. Crops Prod. 43, 827-831.

Singleton V.L., Orthofer R., Lamuela-Raventos R.M., 1999. Analysis of total phenols and other oxidation substrates and antioxidants by means of folin-ciocalteu reagent, Methods Enzymol, Vol. 299; pp 152-178.

Srinivasan R., Chandrasekar M.J.N., Nanjan M.J., Suresh B., 2007. Antioxidant activity of Caesalpinia digyna root. J Ethnopharmacol 113:284-91.

Šulniūtè, V., Ragažinskienè, O., \& Venskutonis, P. R. (2016). Comprehensive evaluation of antioxidant potential of 10 salvia species using high pressure methods for the isolation of lipophilic and hydrophilic plant fractions. Plant Foods for Human Nutrition, 71(1), 64-71.

Tahraoui, A., El-Hilaly, J., Israili, Z. H. and Lyoussi, B. 2007. Ethnopharmacological survey of plants used in the traditional treatment of hypertension and diabetes in south-eastern Morocco (Errachidia province). Journal of Ethnopharmacology 110, 105-117.

Taleb-Senouci D., Ghomari H., Krouf D., Bouderbala S., Prost J., Lacaille-Duboisc M.A., Bouchenak, 2009. Antioxidant effect of Ajuga ivaaqueous extract in streptozotocin- 
induced diabetic rats. Phytomedicine, 16, 623-631.

Tsurng-Juhn H, Yi-Yen C, Kuo-Hsiung W,Tsung-Hsin H, and Chang Hung C, 2009. Isolation and characterization of microsatellite loci in Ajuga taiwanensis Nakai ex Murata using PCR-based isolation of microsatellite arrays (PIMA). Botanical Studies, 50, 21-24.
Yusuke I, Norihiko T, Junichi K, Goro K, Tsukasa I, 2013. Flavones and anthocyanins from the leaves and flowers of Japanese Ajuga species (Lamiaceae). Biochemical Systematics and Ecology, 51, 123-129.

Zafar H.I., and Badiâa L. 2009. Ethnopharmacology of the plants of genus Ajuga. Pakistan Journal of Pharmaceutical Sciences, 22(4) 425-462. 